\title{
Research on Constructing a Model of Collaborative Innovation System for Equipment Manufacturing Industry
}

\author{
Baoyu Jia, Xiaonan Chen, Zhaoji Yu and Chuang Wei \\ School of Management,Shenyang University of Technology,Shenyang 110870,China \\ Corresponding author: shengchanjihua999@vip.sina.com
}

\begin{abstract}
In contrast to extant researches, this paper stats from the definition and analysis of manufacturing industry collaborative innovation system. Then, the author constructed a concept model of collaborative innovation system for equipment manufacturing industry. The model consists of a sub-system of cooperation education of government, enterprise, university and scientific research organization(CEGEUSRO), a sub-system of industry chain and a supporting platform system.On the foundation of the concept model,a system dynamic model was developed and simulation experiment was conducted.
\end{abstract}

\section{Introduction}

Liaoning intelligent manufacturing platform was forged to adapt to "Industry 4.0". However, there are still problems such as large but not strong and limited innovation ability. The contradiction between the surplus production capacity in lower or middle industries and the heavy dependence of the import of high-tech major equipment is not resolved [1].

\section{Analysis of mechanism of actions among manufacturing industry collaborative subjects}

On the basis of previous collaborative innovation models, this paper believes that the constructing subjects in a manufacturing industry collaborative innovation system involve the following seven enterprise or non-enterprise social organizations: manufacturing enterprises, government, universities or scientific research organizations, upstream and downstream enterprises in an industry chain, customer, financial institutions of science and technology, and intermediary service agencies [2].

As the real stimulator of market demands, customers play an important promoting role in the innovation of enterprises. Customers of manufacturing enterprises are characterized by centralization, complexity in purchase, and personalized demands. These distinctive features serve as the foundation of the collaboration between customers and manufacturing enterprise.

Technology collaboration and fund collaboration are the two main paths of collaboration between customer and manufacturing enterprises. The basis of collaboration of the technology collaboration path lies in customer's requirement for the improvements in techincal process of original products. Through technology development, enterprises continue upgrading their technologies in the constantly repeated process of "communication- improvementcommunication " until new satisfactory products are produced for customers [3]. The basis of collaboration of the fund 
collaboration path lies in the financial guarantee provided to satisfy customers' demand for new products as well as enterprises' development of new products and expanded reproduction in the trading of products.

Knowledgeable and academic talented individuals gathering in universities and scientific research organizations greatly elevated the success rate and output rate of fundamental researches. Enterprises have advantages in the later stage of technology innovation, such as application research, research and development of products, and industrialization [4].

Enterprises' demand for technology is transferred to universities via the platform. Scientific research team in university develops new technologies that fit the demand of equipment manufacturing enterprise, consequently improve the competitiveness of enterprises. Meanwhile, talented individual output is another important collaboration path between universities and enterprises.

Intermediary service agencies serve as the adhesive among various innovation main bodies and the catalyst in the process innovation. They bridge the gaps in a collaborative innovation system [5].

After processing the technology, talented individual and industry development information gathered from the market [6], intermediary service agencies published them in digital form on intermediary service platform to satisfy enterprises' demand for specific innovation resource.

The financial system of science and technology is a service system aiming to combine science [7] and technology innovation with the capital chain and to stimulate the mutual promotion of the two [8].

Government financial departments and science and technology management department are the two major public financial main bodies of science and technology [9]. Through fiscal policy, government supports science and technology innovation of equipment manufacturing enterprises by direct science and technology appropriation [10]. Fiscal investment focuses on aiding the development of industry rather than gaining profits. Market financial main body of science and technology applies the principle of profit maximization to the investment in equipment manufacturing enterprises [11], therefore, it makes preferential investments. Whether in public financial system of science and technology or in the market financial system of science and technology, capital will be recycled in the process of collaboration [12]. The collaborative effect between the two parties will form a virtuous cycle and strengthen inner bodies in the system [13].

A complete industry chain contains processing of raw materials, production of intermediate products, product production, sales, and customers [14]. Every one of these five links can be considered as a node, and is made up of enterprises similar in nature. Studies showed that the equipment manufacturing industry chain is composed by upstream, middle stream and downstream enterprises [15]. Raw material manufacturers are the upstream enterprises. Middle ware manufacturers like component manufacturers and spare part manufacturers are middle stream enterprises. Module manufacturers and integrated manufacturers are downstream enterprises which ultimately serve customer [16].

When a customer makes a new demand for the technology of a product, based on features of the new product, downstream enterprises will submit improvement request to middle stream and upstream enterprises. Middle stream and upstream enterprises will upgrade the technology and integrate semi-finished products with downstream enterprise to produce the product the customer needed.

With the continuous development of modern market economy in China, the roles of government and market in resource allocation have changed. It has completed the transformation from "total planned economy" to "planned economy supplemented by market regulation" and finally to "market plays a decisive role”. Government should admit the decisive role market mechanism plays in the development of equipment manufacturing industry, and take full advantage of overall planning to guide the sustained and healthy development of equipment manufacturing industry by taking active fiscal, currency, price and industry policies.

The collaborative paths between government and equipment manufacturing enterprise can be divided into direct path and indirect path. Direct collaboration refers to the direct collaborative effect between government and equipment manufacturing enterprises. Government promote the development of equipment manufacturing enterprises by formulating and implementing industrial policies. Indirect collaboration refers to the guarantee service provided by 
government to ensure the rapid development of enterprises. It takes effect through optimizing supporting measures of the environment rather than direct collaboration with enterprises.

\section{The construction of system dynamic model for collaborative innovation system for equipment manufacturing industry}

\subsection{System Boundary Determination}

The system dynamic model for collaborative innovation system for equipment manufacturing industry this study constructed is composed of CEGEUSRO sub-system, supporting platform sub-system, and industry chain sub-system.

\subsection{Basic Hypotheses}

Hypothesis 1 . The operation process of the system is not influenced by irresistible factors such as natural disasters or wars.

Hypothesis 2. The system operates in a continuous and gradual process during a period time from past to future.

Hypothesis 3. The intensity of collaboration between equipment manufacturing enterprise and university and scientific research organization is reflected by the proportion of enterprise investment into the R\&D of university and scientific research organization.

Hypothesis 4 . The number of patent application can fully reflect the innovation ability of equipment manufacturing enterprises. It can also be used to measure the overall operation effect of the collaborative innovation system for equipment manufacturing industry. It is the only representing variable of system output.

Hypothesis 5. The influence of upstream and downstream enterprises on innovation of equipment manufacturing enterprises is represented by "Income from New Product Sale" .

Hypothesis 6. The service level of intermediary service agency is reflected by the information level of the environment an enterprise is in.

Hypothesis 7. University or scientific research organization pay back the corporate funding in R\&D in form of paten transform.

\subsection{The construction of causality loop chart and flow char of the model}

Based on the analysis of internal components in the three sub-systems, this paper drafted the causality loop model of collaborative innovation system for equipment manufacturing industry, shown in Figure 1. The causality loop model is the integration of the causality loops of the three sub-systems. It vividly described the causality relationship among sub-systems and among components within the collaborative innovation system for equipment manufacturing industry.

To clearly illustrate the influence of different factor on the number of patent application of equipment manufacturing enterprise, this paper designed the following feedback circle to illustrate major feedback loops of the causality loop model. On the basis of previous causality loop model, this paper further put forward the flow chart model of the system to fully apprehend the internal structure and characteristics of dynamic behavior of the system. 


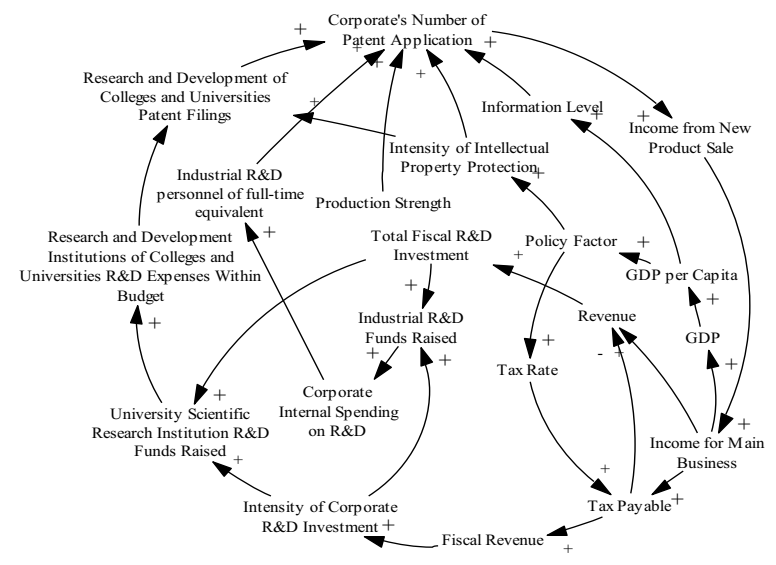

Fig.1. The causality loop model of collaborative innovation system for equipment manufacturing industry.

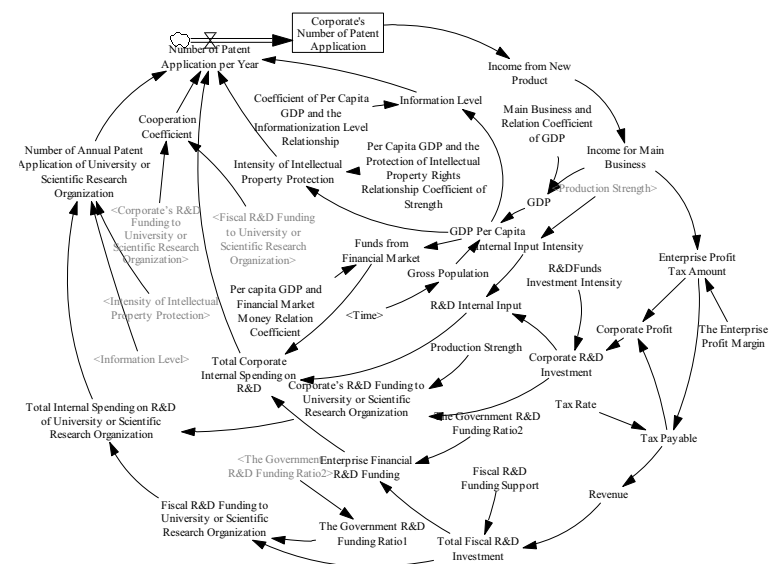

Fig.2. Flow chart model of collaborative innovation system for equipment manufacturing industry.

\section{System Dynamic Simulation of the Collaborative Innovation System for Equipment Manufacturing Industry}

\subsection{The simulation of number of annual patent application of equipment manufacturing enterprise from 2014 to 2020}

The aim of this experiment was to evaluate the general operation effect of the collaborative innovation system for equipment manufacturing industry when the innovation elements that all the collaborative main bodies invested in remained the same in future years. During the experiment process, no parameters in the dynamic model were altered, the model was run naturally to output the number of annual patent application from 2014 to 2020. The results are shown in Table 1.

Table 1. The increase rate of patent application from 2014 to 2020.

\begin{tabular}{cccccccc}
\hline Year & 2014 & 2015 & 2016 & 2017 & 2018 & 2019 & 2020 \\
\hline $\begin{array}{c}\text { Number of Annual } \\
\text { Patent Application }\end{array}$ & 407614 & 488099 & 584971 & 701811 & 843098 & 1014480 & $\begin{array}{c}122315 \\
6 \\
\text { Growth Rate }\end{array}$ \\
$\begin{array}{c}19.664 \\
\%\end{array}$ & $\begin{array}{c}19.745 \\
\%\end{array}$ & $19.847 \%$ & $19.974 \%$ & $\begin{array}{c}20.132 \\
\%\end{array}$ & $20.328 \%$ & $\begin{array}{c}20.570 \\
\%\end{array}$ \\
\hline
\end{tabular}


The result shows that if the collaborative innovation system remain the same level, from the seven years between 2014 and 2020, the innovation ability of equipment manufacturing enterprise in China will steadfastly elevated with an increasing rate of $20.037 \%$. This reflects a strong momentum for growth of the integral innovation ability of equipment manufacturing enterprise.

\subsection{Simulation of Variable's Sensitivity}

This simulation experiment was designed to determine sensitive factors that influenced the effect of collaborative innovation system for equipment manufacturing industry. The purpose was to identify the most influential and most sensitive variable to conduct further analysis to predict or estimate its degree of influence. The detection of the root of uncertainties would be the decision basis for effective countermeasures. Variables in this sensitivity analysis included funds from financial market, income from new product sale, information level, intensity of intellectual property protection, tax rate, strength of fiscal $\mathrm{R} \& \mathrm{D}$ funding support. The number of annual patent application was used as representing variable to measure the variables' sensitivity. To prepare for sensitivity analysis, judgment of positive or negative correlation between every variable and representing variables was carried out before sensitivity analysis.

(1) Analysis of the influence of variation of single variable on the number of patent application

The positive or negative influence of the variable on collaborative innovation system for equipment manufacturing industry was judged by measuring the variation of the representing variable when the amount of variation of a single variable was adjusted.

1) Analysis of the variation in corporate $R \& D$ investment

The intensity of corporate R\&D investment was set to increase by $2 \%, 4 \%, 6 \%, 8 \%$, and $10 \%$.

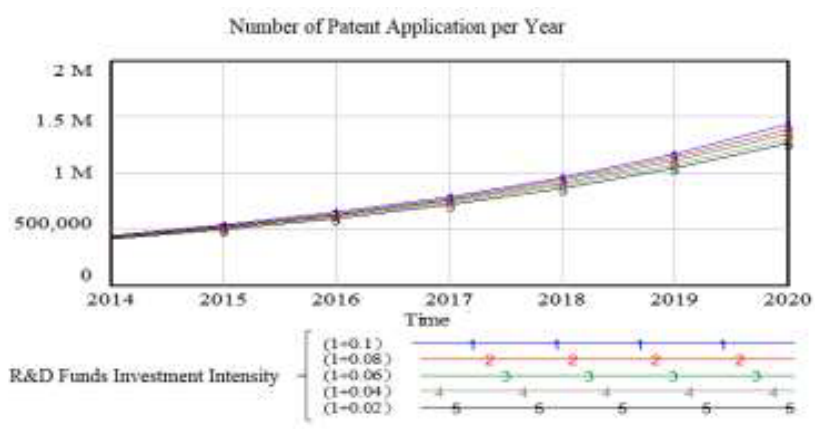

Fig.3. The influence of corporate R\&D investment on number of patent application.

The result showed that, the number of patent application increased along with the increase of corporate R\&D investment. This indicates that corporate $R \& D$ investment has a positive promoting effect on number of patent application. When the intensity of corporate R\&D investment elevated, the money spent on R\&D increased, and consequently, the corporate' s number of patent application increased accordingly.

2) Analysis of the variation of total fiscal R\&D investment

The strength of fiscal R\&D funding support was set to increase by $2 \%, 4 \%, 6 \%, 8 \%$, and $10 \%$, the result of the output of number of annual patent application is shown in Table 2 .

Table 2. The influence of total fiscal R\&D investment on number of patent application.

\begin{tabular}{cccccc}
\hline Year & $\begin{array}{c}\text { Funding } \\
\text { Support } \\
(1+0.1)\end{array}$ & $\begin{array}{c}\text { Funding } \\
\text { Support } \\
(1+0.08)\end{array}$ & $\begin{array}{c}\text { Funding } \\
\text { Support } \\
(1+0.06)\end{array}$ & $\begin{array}{c}\text { Funding } \\
\text { Support } \\
(1+0.04)\end{array}$ & $\begin{array}{c}\text { Funding } \\
\text { Support } \\
(1+0.02)\end{array}$ \\
\hline 2014 & 409215 & 408933 & 408652 & 408372 & 408093 \\
2015 & 490412 & 489997 & 489584 & 489172 & 488762 \\
\hline
\end{tabular}




\begin{tabular}{llllll}
\hline 2016 & 588287 & 587684 & 587083 & 586484 & 585887 \\
2017 & 706545 & 705673 & 704804 & 703939 & 703077 \\
2018 & 849836 & 848582 & 847333 & 846088 & 844848 \\
2019 & 1024065 & 1022265 & 1020471 & 1018684 & 1016904 \\
2020 & 1236798 & 1234214 & 1231640 & 1229076 & 1226524 \\
\hline
\end{tabular}

The result showed that, the number of patent application increased along with the increase of total fiscal $R \& D$ investment. This indicates that total fiscal R\&D investment has a positive promoting effect on number of patent application. The inflow of capital from government total fiscal R\&D investment an enterprise received, increased corporate internal spending on $\mathrm{R} \& \mathrm{D}$ and resulted in the increase in the number of patent application.

3) Analysis of variation in tax revenue

The tax rate was set to decrease by $2 \%, 4 \%, 6 \%, 8 \%$, and $10 \%$, the result of the output of number of annual patent application is shown in Table 3.

Table 3. The influence of tax rate on number of patent application.

\begin{tabular}{cccccc}
\hline Year & Rate (1-0.1) & $\begin{array}{c}\text { Rate } \\
(1-0.08)\end{array}$ & $\begin{array}{c}\text { Rate } \\
(1-0.06)\end{array}$ & $\begin{array}{c}\text { Rate } \\
(1-0.04)\end{array}$ & $\begin{array}{c}\text { Rate } \\
(1-0.02)\end{array}$ \\
\hline 2014 & 406282 & 406574 & 406873 & 407180 & 407494 \\
2015 & 485970 & 486423 & 486888 & 487365 & 487853 \\
2016 & 581655 & 582345 & 583055 & 583783 & 584529 \\
2017 & 696734 & 697774 & 698843 & 699940 & 701066 \\
2018 & 835420 & 836973 & 838569 & 840208 & 841889 \\
2019 & 1002970 & 1005274 & 1007643 & 1010076 & 1012572 \\
2020 & 1206006 & 1209409 & 1212908 & 1216504 & 1220196 \\
\hline
\end{tabular}

The result showed that, the number of patent application of equipment manufacturing enterprise was mildly influenced by decease of tax rate. The analysis of causality feedback loop indicated that on the one hand the reduced tax promoted the equipment manufacturing enterprise' $s$ total investment into $R \& D$, on the other hand, it reduced government revenue. Since the government' s R\&D funding ratio of equipment manufacturing enterprise remained the same, as a result, the R\&D funding equipment manufacturing enterprise received from the government was influenced. The simulation results told us that equipment manufacturing enterprise' $s$ total internal spending on R\&D was affected, and ultimately influenced the output of patent application of equipment manufacturing enterprise. This indicated that though the adjustment of tax rate could increase corporate R\&D investment, it was corporate R\&D spending that directly influenced corporate' $s$ number of patent application. Besides, other factors also influenced corporate' $s$ total R\&D spending, such as the amount of government funding, fund from financial market, etc.

4) Analysis of the variation in funds from financial market

The amount of funds from financial market was set to increase by 2 times, 4 times, 6 times, 8 times, and 10 times. The result showed that, the number of patent application increased together with the increase of financial market' $\mathrm{s}$ investment. This indicates that fund from financial market has a positive promoting effect on number of patent application. Fund from financial market is an important capital guarantee of corporate' s increase in investment, it can share corporate' s innovation R\&D risk.

5) Analysis of the variation in income from new product sale 
The income from new product sale was set to increase by $2 \%, 4 \%, 6 \%, 8 \%$, and $10 \%$.

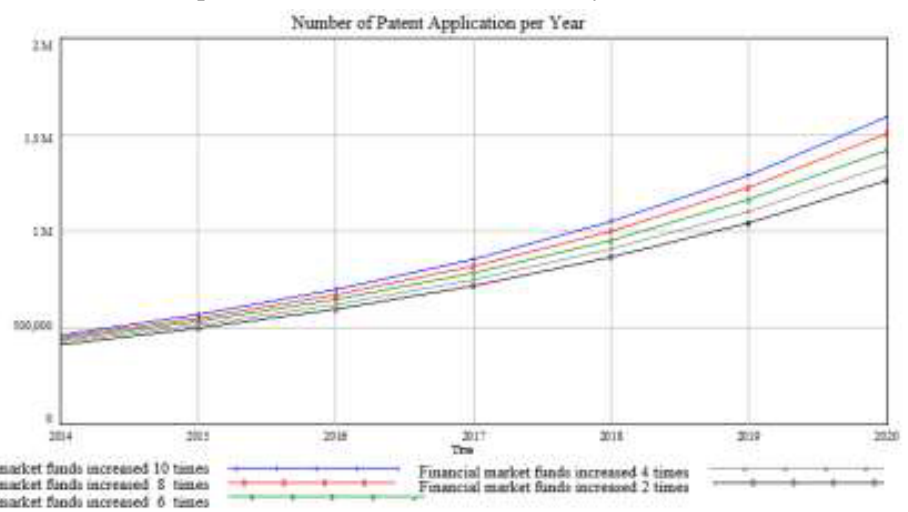

Fig.4. The influence of funds from financial market on number of patent application.

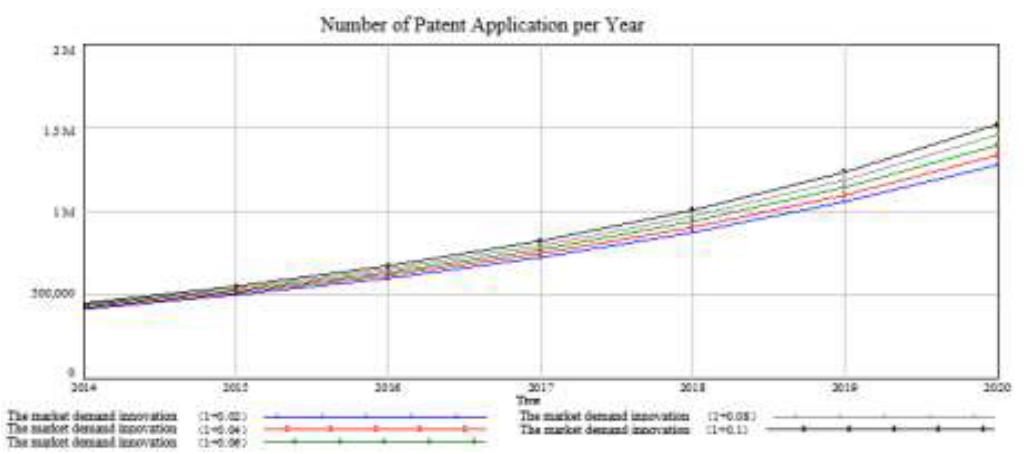

Fig.5. The influence of income from new product sale (customer demand for innovation) on number of patent application.

The result showed that, the number of patent application increased as income from new product increased. This indicates that income from new product sale has a positive promoting effect on number of patent application. Income from new product sale reflects customer' s demand for innovation. Corporate can gain a high additional profit above general product. As a result, the increase in profit encourages corporate' $s$ enhancement of the investment in technology improvement to better satisfy customer' $s$ demand for innovation, thus corporate' $s$ innovation ability is constantly elevated.

6) Analysis of variation in information level

The information level was set to increase by $2 \%, 4 \%, 6 \%, 8 \%$, and $10 \%$, the result of the output of number of annual patent application is shown in Table 4.

Table 4. The influence of information level on number of patent application.

\begin{tabular}{cccccc}
\hline Year & Level $(1+0.1)$ & Level $(1+0.08)$ & Level $(1+0.06)$ & Level $(1+0.04)$ & Level $(1+0.02)$ \\
\hline 2014 & 417027 & 415185 & 413342 & 411500 & 409657 \\
2015 & 500452 & 498029 & 495607 & 493187 & 490769 \\
2016 & 601081 & 597913 & 594751 & 591593 & 588441 \\
2017 & 722719 & 718601 & 714492 & 710391 & 706300 \\
2018 & 870143 & 864806 & 859485 & 854179 & 848888 \\
2019 & 1049391 & 1042491 & 1035615 & 1028763 & 1021936 \\
2020 & 1268184 & 1259270 & 1250393 & 1241553 & 1232750 \\
\hline
\end{tabular}


The result showed that, the number of patent application increased in accordance with the improvement of information level. This indicates that information level has a positive promoting effect on number of patent application.

\section{Conclusion}

\subsection{For Enterprises}

\subsubsection{Increase R\&D Investment}

Firstly, equipment manufacturing enterprise should cultivate the innovative consciousness of "Science and technology constitute a primary productive force” and grasp the concept that the corporate' s core competitiveness is founded on technology R\&D and new product R\&D. They should fully realize that technology innovation is of vital importance to the development of an enterprise. Secondly, a special R\&D fund should be set up in guarantee the sustainability of R\&D investment. Lastly, under the guidance of government' $s$ macro industry policies, enterprises should actively cooperate with financial main body in the market to expand $\mathrm{R} \& \mathrm{D}$ financing resources.

\subsubsection{Fastened the integration of enterprises and informatization}

The result of simulation indicated that information level crucially promote the innovation ability of equipment manufacturing industry. At present, fastening the integration of informatization and industrialization has become a fundamental policy on equipment manufacturing industry in Liaoning Province. For an equipment manufacturing enterprise, on the one hand, investment in informatization should be increased so that complete informatization covering product $\mathrm{R} \& \mathrm{D}$, production and sale can be realized by more advance information technologies. On the other hand, cultivation of talents in informatization should be improved to guide the integration between equipment manufacturing technology and information technology. Lessons can be drawn from overseas experience. There is plenty room to explore in the cooperation between universities and enterprises, university can cultivate talents for enterprises.

\subsubsection{Promote cooperation with university and scientific research organization}

The simulation result indicated that equipment manufacturing enterprises can enhance innovation efficiency by the cooperation with university and scientific research organization. Universities and scientific research organizations have advantages in original innovations. Whereas the advantages of equipment manufacturing enterprise lie in the application research and industrialization.

\subsection{For Government}

\subsubsection{Establish a multi-source financing system}

Government should explore more channels of financing for enterprises. The establishment of a multi-direction and multi-layer financing system will guarantee the sufficiency of funds to invest in the research and development of technology. Special attention should be paid to small and medium-size enterprises with stronger innovation vigor. These enterprises have remarkable innovation abilities. The guarantee of sufficient R\&D funds is an important approach to improve innovation efficiency. In the meantime, government should promote the cooperation between enterprises and organization in financial market and other aspects of the society. Innovation risk fund of the industry should be created to share risk for enterprise innovation. 
A more complete intellectual property protection system necessarily safeguards the fruit of corporate innovation. The result of simulation revealed that the intensity of intellectual property protection can extremely encourage corporate' $\mathrm{s}$ passion of innovation and produce a lasting effect on the number of corporate' s patent application. Government should create a serious atmosphere of being protected by laws in the society. Government should raise corporates' consciousness using law to protect themselves and teach them to keep their economic interests intact by using laws.

\subsubsection{Build a favorable demand market for enterprises}

The products produced by equipment manufacturing enterprise in our province have no advantages in the competition with products from developed countries because the technology contained in the products of is not high enough and the added value of products is low. This explains enterprises' incompetence Many enterprises, no matter how strong the intention of developing new product is, were forced to converted into accessory manufactures at the end of value chain. A favorable demand market built by government can promote the product sale made by domestic equipment manufacturing enterprises by means of lowing value-added tax. The market can support the export of innovative products from independent brands with core technology by the comprehensive application of export drawback. Besides government should take policy measures such as further increasing the proportion of purchase. As a result, the expanded demand market will promote the sale of products made by equipment manufacturing enterprises. In the meantime, the product and capital turnover rate will be improved so that the capital the corporate technology innovation needed will be guaranteed.

\section{References}

1. Michael T, Mark A.V, Jeen S L. Manufacturing technology and strategy formulation: keys to enhancing competitiveness and improving performance.Journal of Operations Management, 1999 (17): 411-428.

2. Gilbert B A. Knowledge spillovers and new venture performance: an empirical examination. Journal of Business Venturing, 2008, 23(4):405-422.

3. Hersh D. Manufacturing Matter.IEEE Engineering Management Review, 2003, 31(3):3-10.

4. Corbett L. Grappling with a Gusher Manufacturing`s Response to Business Success in Small and Medium Enterprises. Journal of Operations Management, 2002, 20(5):495-517.

5. Hyun-Sun R, Jung L. How Non-technological Innovation Reinforces the Effect of Technological Innovation on Firm Performance: An Empirical Study of Korean Manufacturing Industry. Communications in Computer and Information Science, 2015(10):176-182.

6. Patricia A. Eco-innovation on Manufacturing Industry: The Role of Sustainability on Innovation Processes.Greening of Industry Networks Studies, 2014(4):99-116.

7. Jose M B. Innovation in the Portuguese Manufacturing Industry: Analysis of a Longitudinal Company Panel. International Advances in Economic Research, 2005(11):301-314.

8. Marek V. Innovation behavior of firms in a small open economy: the case of the Czech manufacturing industry. Empirical, 2015(20):1-29.

9. Candace E, Thomas A. Turk. The evolution of trust in information technology alliances. Journal of High Technology Management Research, 1998(20):62-74.

10. Porter M E. The Competitive Strategy of Nations. New York: The Free Press, 1990.

11. Hacklin F, Marxt C, Fahrni F. Strategic venture partner selection for collaborative innovation in production systems: A decision support system-based approach. International Journal of Production Economics, 2006, 104(1):100-112. 
12. Islam N, Ozcan S. Nanotechnology Innovation System: An Empirical Analysis of the Emerging Actors and Collaborative Networks. IEEE Transactions on Engineering Management, 2013, 60(4):687-703.

13. Fang Q, Zheng J G. Structure characteristics of collaborative innovation system and its implementation paths Based on interpretative structural model. Economist, 2015.

14. Jian-Zhong X U, Zhao W F, Wang L J. Analysis of the Relationship among Agents of Collaborative Innovation System in Equipment Manufacturing Industry Based on Game Theory. China Soft Science, 2014.

15. Bambini M D, Coltri P P, Furtado A T, et al. Collaborative Innovation in Agrometeorology: Coordination Strategies to Develop a Monitoring IT System for Brazil. Journal of Technology Management \& Innovation, 2014, 9(1):119-130.

16. Zhao Y, Ke L V. Construction and Implementation of Information Resources Allocation System for Collaborative Innovation. Information Science, 2013, 4(13):109-117. 